\title{
Magnetic resonance imaging traits may help to differentiate Pelizaeus-Merzbacher and Pelizaeus-Merzbacher-like disease
}

Características em ressonância magnética podem auxiliar a diferenciar doença de Pelizaeus-Merzbacher e Pelizaeus-Merzbacher-like

Matheus Augusto Araújo CASTRO', Pedro Henrique Almeida FRAIMAN', Clecio de Oliveira GODEIRO-JUNIOR

A six-year-old boy with nystagmus and developmental delay from six months of age, was born from healthy firstdegree cousins. On neurological examination, he presented with spontaneous and multidirectional nystagmus, gait and upper limb ataxia, and lower limb hyperreflexia/spasticity. Brain magnetic resonance disclosed a hypomyelinating pattern (Figure). Pelizaeus-Merzbacher disease was considered, although there was unusual pontine dysmyelination. Pelizaeus-Merzbacher disease was excluded as the PLP1 gene sequencing was negative. Pelizaeus-Merzbacher-like disease was considered, and a homozygous mutation in GJC2 gene (c.217C > A p.[P73T]) was found. Pontine dysmyelination is not usually described in Pelizaeus-Merzbacher disease and may be a clue to Pelizaeus-Merzbacher-like disease ${ }^{1,2}$.

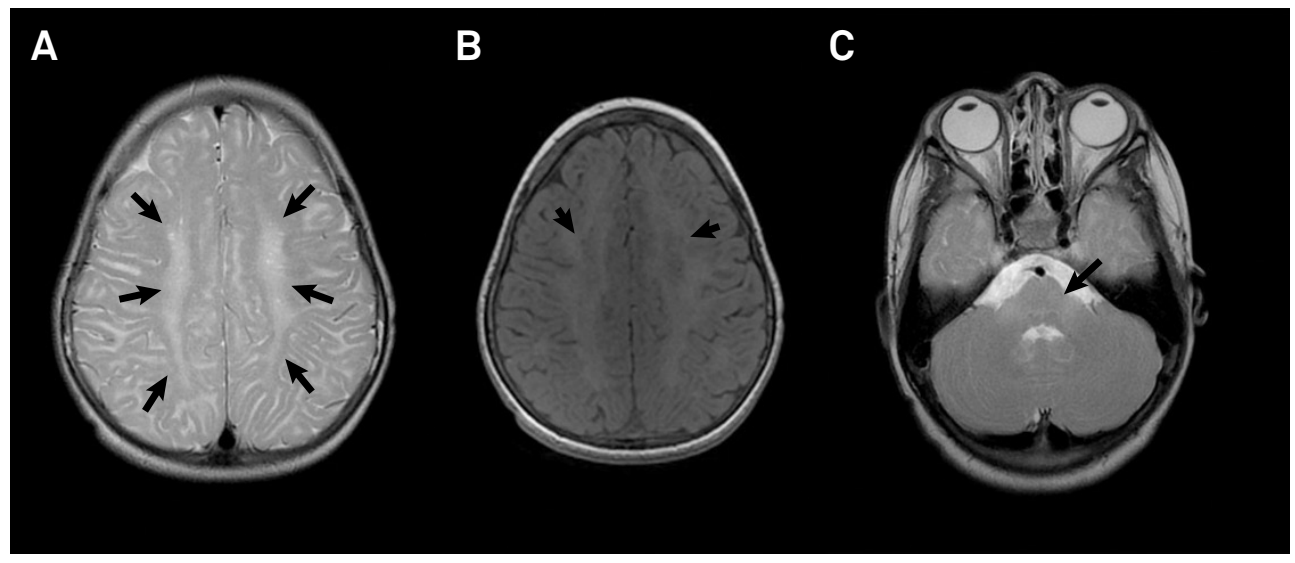

Figure. Magnetic resonance features of Pelizaeus-Merzbacher-like disease: (A) Diffuse T2 hyperintensity (hollow arrow) and (B) T1 slight hypointensity of cerebral white matter (arrowhead), characterizing hypomyelination; and (C) pontine T2 hyperintensity (white arrow), highly compatible with Pelizaeus-Merzbacher-like disease ${ }^{2}$

1. $\quad$ Akinaga K, Lee TY, Montenegro MA. Pelizaeus Merzbacher disease: dysmyelination versus demyelination. Arq Neuropsiquiatr. $2016 \mathrm{Jan} ; 74(1): 81$.

https://doi.org/10.1590/0004-282X20150170
2. Steenweg ME, Vanderver A, Blaser S, Bizzi A, Koning TJ, Mancini $\mathrm{GM}$, et al. Magnetic resonance imaging pattern recognition in hypomyelinating disorders. Brain 2010 Oct;133(10):2971-82. https://doi.org/10.1093/brain/awq257

\footnotetext{
Universidade Federal do Rio Grande do Norte, Departamento de Medicina Integrada, Natal RN, Brasil.

Matheus Augusto Araújo Castro (iD) https://orcid.org/0000-0003-0335-8799; Pedro Henrique Almeida Fraiman (iD) https://orcid.org/0000-0002-5250-8602; Clecio de Oliveira Godeiro-Junior (iD) https://orcid.org/0000-0002-4312-1633

Correspondence: Clecio Godeiro-Junior; Av. Nilo Peçanha, S/N - Petropolis; 59012-300 Natal RN, Brasil; E-mail: cleciojunior@yahoo.com.br Conflict of interest: There is no conflict of interest to declare.

Received 23 January 2019; Received in final form 19 February 2019; Accepted 10 March 2019.
} 